\title{
Stem/Progenitor Cells Derived from the Cochlear Sensory Epithelium Give Rise to Spheres with Distinct Morphologies and Features
}

\author{
Marc Diensthuber, ${ }^{1,2}$ Kazuo Oshima, ${ }^{1}$ and Stefan Heller ${ }^{1}$ \\ ${ }^{1}$ Departments of Otolaryngology-Head E Neck Surgery and Molecular E Cellular Physiology, School of Medicine, Stanford University, \\ 801 Welch Road, Stanford, CA 94305-5739, USA \\ ${ }^{2}$ Department of Otorhinolaryngology, Hannover Medical University, Carl-Neuberg-Straße 1, 30625, Hannover, Germany
}

Received: 17 September 2008; Accepted: 5 February 2009; Online publication: 27 February 2009

\begin{abstract}
Nonmammalian vertebrates regenerate lost sensory hair cells by means of asymmetric division of supporting cells. Inner ear or lateral line supporting cells in birds, amphibians, and fish consequently serve as bona fide stem cells resulting in high regenerative capacity of hair cell-bearing organs. Hair cell regeneration does not happen in the mammalian cochlea, but cells with proliferative capacity can be isolated from the neonatal cochlea. These cells have the ability to form clonal floating colonies, so-called spheres, when cultured in nonadherent conditions. We noticed that the sphere population derived from mouse cochlear sensory epithelium cells was heterogeneous, consisting of morphologically distinct sphere types, hereby classified as solid, transitional, and hollow. Cochlear sensory epithelium-derived stem/progenitor cells initially give rise to small solid spheres, which subsequently transition into hollow spheres, a change that is accompanied by epithelial differentiation of the majority of sphere cells. Only solid spheres, and to a lesser extent, transitional spheres, appeared to harbor self-renewing stem cells, whereas hollow spheres could not be consistently propagated. Solid spheres contained significantly more rapidly cycling Pax-2-expressing presumptive otic progenitor cells than hollow spheres. Islet-1, which becomes upregulated in nascent sensory patches, was also more
\end{abstract}

Correspondence to: Stefan Heller - Departments of OtolaryngologyHead \& Neck Surgery and Molecular \& Cellular Physiology, School of Medicine $\cdot$ Stanford University $\cdot 801$ Welch Road, Stanford, CA 943055739, USA. Telephone: +1-650-7248086; fax: +1-650-7258502; email: hellers@stanford.edu abundant in solid than in hollow spheres. Likewise, hair cell-like cells, characterized by the expression of multiple hair cell markers, differentiated in significantly higher numbers in cell populations derived from solid spheres. We conclude that cochlear sensory epithelium cell populations initially give rise to small solid spheres that have self-renewing capacity before they subsequently convert into hollow spheres, a process that is accompanied by loss of stemness and reduced ability to spontaneously give rise to hair celllike cells. Solid spheres might, therefore, represent the most suitable sphere type for cell-based assays or animal model transplantation studies aimed at development of cell replacement therapies.

Keywords: inner ear, regeneration, hair cell, supporting cell, organ of Corti, stem cell

\section{INTRODUCTION}

Hair cell-bearing sensory organs are used by virtually all metazoan life forms for the detection of mechanical stimuli (Holtmann and Thurm 2001; Watson and Mire 1999). Throughout the animal kingdom, these organs have maintained bona fide stem cell niches, which provide regenerative capacity to replace lost sensory hair cells throughout the life of the individual animal (Corwin 1981, 1985; Corwin and Cotanche 1988; Cruz et al. 1987; Lopez-Schier and Hudspeth 2006; Ryals and Rubel 1988). Mammals, however, a small but relevant subclass of chordates, appear to have lost the ability to maintain stem cells in their 
hearing organs. This loss is manifested by the permanence of auditory hair cell loss and its consequence: deafness. Nevertheless, the remnant of the once powerful regenerative ability can be detected in the mammalian adult vestibular sensory epithelia as well as in the neonatal cochlea. Particularly, it has been possible to isolate self-renewing progenitor cells from these organs and to use the progeny of these cells to generate hair cell-like cells in vitro and in vivo (Li et al. 2003; Oshima et al. 2007; Savary et al. 2007; Savary et al. 2008; Senn et al. 2007; White et al. 2006; Zhai et al. 2005; Zhang et al. 2007). These inner earderived stem/progenitor cells are probably well-suited for proof-of-principle experiments aimed to replace lost hair cells in the organ of Corti, if the hurdles of cell delivery and proper cell homing could be overcome.

A valuable technique for the isolation of stem/ progenitor cells from the inner ear's sensory epithelia is the sphere formation assay ( $\mathrm{Li}$ et al. 2003; Malgrange et al. 2002), which is derived from the neurosphere assay used to isolate multipotent and self-renewing stem cells from the mammalian central nervous system (for review, see Reynolds and Rietze 2005). Sphereforming otic stem/progenitor cells display a distinct capacity to divide in nonadherent culture conditions, which results in the formation of clonal floating colonies (spheres). These spheres can be propagated, the sphere-derived cells express marker genes of the developing ear and nervous system, and sphere cells are capable of differentiating into a variety of different cell types, including supporting and hair cell-like cells (Li et al. 2003; Oshima et al. 2007; Savary et al. 2008; Senn et al. 2007; Zhai et al. 2005; Zhang et al. 2007). Sphere-forming otic progenitor cells are not only an excellent tool for in vitro developmental studies but they are also an important cell source for transplantation studies into damaged inner ears of animal models with the long-term objective of developing cell-based replacement therapies.

Cochlear cell-derived spheres have been isolated and characterized by several laboratories and we noticed a considerable diversity in the reported morphology of spheres derived from inner ear sensory epithelium preparations (compare $\mathrm{Li}$ et al. 2003; Oshima et al. 2007; Savary et al. 2007; Savary et al. 2008; Senn et al. 2007; Zhai et al. 2005; Zhang et al. 2007). This observation raised the question about the origin and the propagation/differentiation potential of the different sphere types that grow from the neonatal organ of Corti. In this study, we provide an in-depth characterization of the different sphere morphologies that form in low-density nonadherent cultures of cochlear sensory epithelium cells. We found a distinct and stereotypic pattern of sphere growth and maturation. Cochlear sensory epithelium- derived progenitor cells initially give rise to compact solid/round spheres that gradually convert into irregular and partially hollow spheres, and ultimately, they form large hollow spheres. We found that the different sphere types express different markers and that they display different propagation and differentiation potential. Our results also suggest that the different sphere types are not derived from different progenitor cell types, but rather, they are the product of a single proliferating progenitor cell that initially grows into a solid compact sphere, which subsequently converts into the other sphere types.

\section{METHODS}

\section{Animals and cochlear dissection}

We used newborn postnatal day 1 (P1) BALB/c mice and Math-1/nuclear green fluorescence protein (nGFP) transgenic mice, which express nGFP under the control of an Atohl enhancer (Lumpkin et al. 2003). For each experiment, we dissected from three to four mice the cochlear sensory epithelia (Fig. 1). This was initiated by dissection of the temporal bone and followed by the removal of the otic bulla to visualize the otic capsule. After excision of the cartilaginous otic capsule, the membranous labyrinth was exposed and the cochlear duct was retrieved. The cochlear epithelial sheet was microdissected from the Reissner's membrane, the spiral ligament, and the stria vascularis. Dissected cochlear sensory epithelia were comprised of the organ of Corti, the greater epithelial ridge (GER), and the lesser epithelial ridge (LER), including cells that, in the mature animal, will contribute to part of the spiral limbus, the inner marginal cell layer, as well as the Hensen's, Claudius', and Boettcher's cells. The sheets were carefully inspected, rinsed in sterile, chilled Hanks' balanced salt solution, and then processed for cell dissociation. Sensory epithelial sheets from Math-1/nGFP mice were further inspected for the presence of nGFP in hair cell nuclei. Animal studies were conducted under an approved institutional protocol according to the National Institutes of Health guidelines.

\section{Cell dissociation and sphere generation}

Two cochlear epithelial sheets were transferred into a $100-\mu \mathrm{L}$ drop of $0.125 \%$ trypsin/ethylenediaminetetraacetic acid (EDTA) (Invitrogen, Carlsbad, CA, USA) in phosphate-buffered saline (PBS; $\mathrm{pH}$ 7.2) and incubated for $5 \mathrm{~min}$ at $37^{\circ} \mathrm{C}$. The enzymatic digest was blocked by adding $100 \mu \mathrm{L}$ of $10 \mathrm{mg} / \mathrm{mL}$ soybean trypsin inhibitor and $1 \mathrm{mg} / \mathrm{mL}$ DNAse I solution (Worthington Biochemical, Lakewood, NY, USA) in Dulbecco's modified Eagle's medium (DMEM)/high 

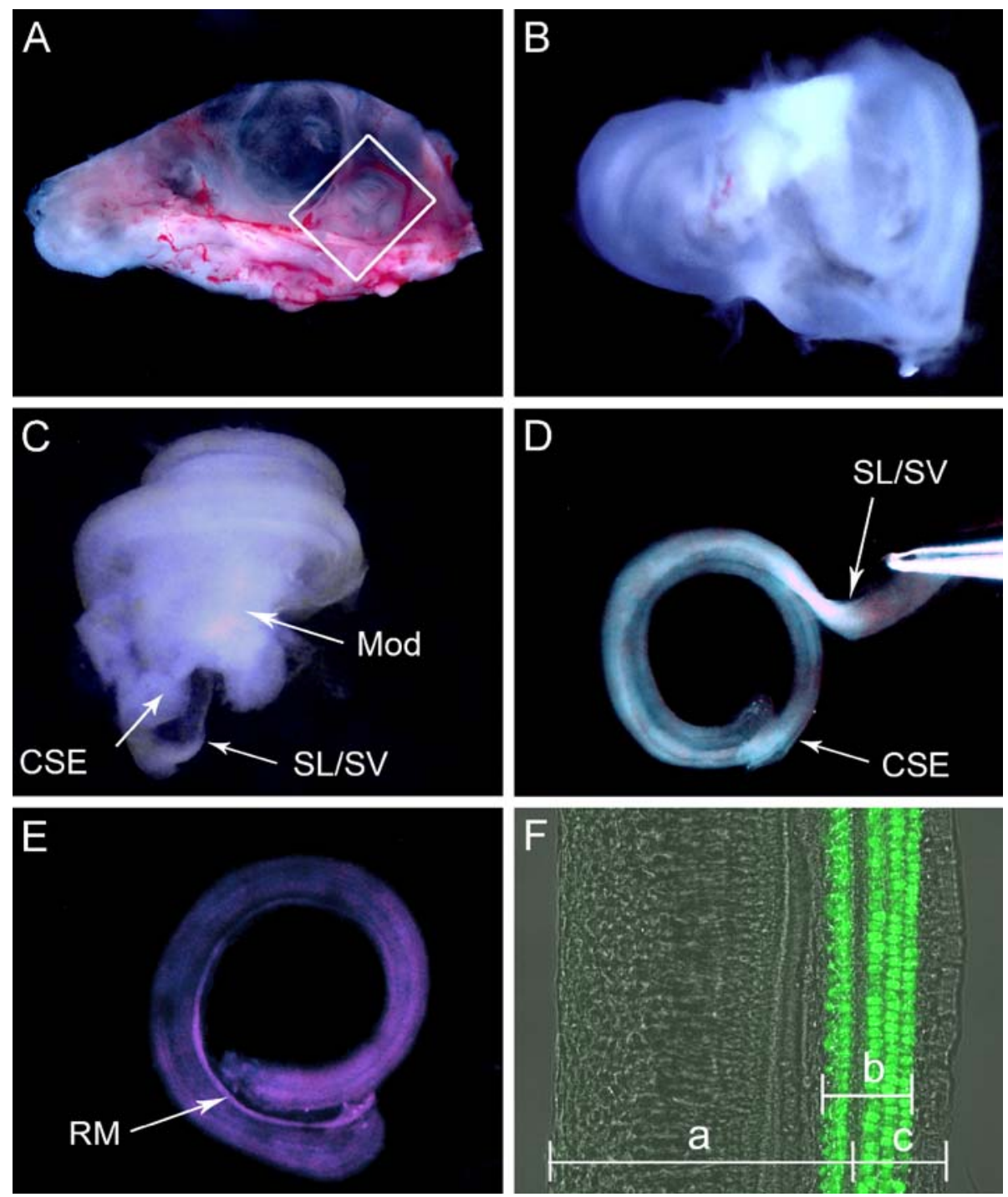

FIG. 1. Dissection of the postnatal day 1 murine cochlear sensory epithelium. A Right hemiskull after removal of the brain. The framed area shows the petrous (temporal) bone which harbors the inner ear organs. B Inner ear with cochlea, after removal of the otic bulla. C Membranous labyrinth of the cochlea, after removal of the bony labyrinth. CSE cochlear sensory epithelium, SL/SV spiral ligament with stria vascularis, Mod modiolus. D The cochlear sensory epithelium is detached from the spiral ligament and the stria vascularis by carefully

tearing these tissues apart. $\mathbf{E}$ View of the cochlear sensory epithelium with the Reissner's membrane $(R M)$. F Epifluorescence and bright field image of the dissected cochlear sensory epithelium composed of the greater (a) and lesser (c) epithelial ridge, including the organ of Corti (b). The inner and outer hair cells display bright green fluorescence, indicative of the nGFP reporter expressed in the nuclei of the Math-1/ nGFP transgenic mouse strain (Lumpkin et al. 2003).

glucose and F12 media (mixed 1:1, Invitrogen). The tissue was triturated carefully $30-50$ times with plastic pipette tips (epTIPS Filter 20-300 $\mu \mathrm{L}$; Eppendorf, Hamburg, Germany) and the resulting cell suspension was microscopically inspected to assess tissue dissociation. The cell suspension was diluted with $2 \mathrm{~mL}$ of sphere culture medium consisting of DMEM/ F12 mixed 1:1 (DMEM-F12) supplemented with N2 and B27 (media and supplements were from Invitrogen), epidermal growth factor $(20 \mathrm{ng} / \mathrm{mL})$, basic

fibroblast growth factor $(10 \mathrm{ng} / \mathrm{mL})$, insulin-like growth factor-1 (50 ng/mL), heparan sulfate $(50 \mathrm{ng} / \mathrm{mL}$ ) (growth factors and heparan sulfate were obtained from R\&D systems, Minneapolis, MN, USA and Sigma, St. Louis, MO, USA), and ampicillin $(50 \mu \mathrm{g} / \mathrm{mL})$. Detailed descriptions of the sphere formation assay can be found in previous publications (Li et al. 2003; Oshima et al. 2009). Cell aggregates were removed by passing of the cells through a $70-\mu \mathrm{m}$ cell strainer (BD Labware, San Jose, CA, USA) directly 
into plastic Petri dishes (suspension culture plate; Greiner Bio-One, Monroe, NC, USA). Ten microliters of the cell suspension were used for the determination of viable cell numbers with trypan blue dye exclusion and a hemocytometer (Neubauer improved). Routinely, we plated the cells obtained from two cochlear epithelial sheets into one $3.5-\mathrm{cm}$ diameter Petri dish. For propagation, we collected 50 spheres and dissociated the cells mechanically after treatment with $0.125 \%$ trypsin/EDTA at $37^{\circ} \mathrm{C}$ for $5 \mathrm{~min}$. Cells were replated in sphere culture medium for 3-5 days to obtain the next generation. This method is feasible for the propagation of inner earderived spheres for up to ten generations $(\mathrm{Li}$ et al. 2003; Oshima et al. 2007; Savary et al. 2008; Senn et al. 2007). Specific analyses were conducted with solid spheres harvested after 3-4 days in vitro (DIV), with transitional spheres collected after 4-6 DIV, and with hollow spheres picked after 6-7 DIV, unless indicated differently.

\section{Cell differentiation}

To study cell differentiation, spheres were individually collected and transferred into plastic four-well tissue culture plates (Greiner $35 / 10 \mathrm{~mm}$ four-well tissue culture dishes) using an inverted microscope and a micromanipulator-guided system (TransferMan NK 2 Micromanipulator; CellTram Oil Microinjector; Eppendorf North America, Westbury, NY, USA) equipped with pulled glass microcapillaries. Tissue culture plates were coated with fibronectin $(20 \mu \mathrm{L} /$ $\mathrm{mL}$; Sigma) for $2 \mathrm{~h}$ and washed with sterile PBS directly before use. Sphere cells were analyzed immediately after attaching to determine uptake of 5-bromo-2'-deoxyuridine (BrdU) during sphere formation, total cell number (after visualizing nuclei with 4',6-diamidino-2-phenylindole [DAPI; Invitrogen]), as well as to characterize the expression of markers. For differentiation, we maintained the attached spherederived cells in a humidified incubator in a $5 \% \mathrm{CO}_{2}$ atmosphere at $37^{\circ} \mathrm{C}$ in differentiation medium consisting of DMEM-F12 supplemented with N2, B27, and ampicillin. Eighty percent of the medium was replaced every 3 days. The differentiated cells were analyzed by immunocytochemistry 14 days after plating. To ensure that hair cell-like cells were newly generated in vitro during the differentiation period, we used transgenic Math-1/nGFP mice for the differentiation assay. Sphere-derived cell populations were observed for nGFP fluorescence after attaching (6 $\mathrm{h}$ after plating) and only cultures devoid of nGFPpositive cells were used to study hair cell differentiation in vitro.

\section{Antibodies}

The following primary antibodies were used: polyclonal guinea pig antibodies to myosin VIIa $(1: 2,000$; Oshima et al. 2007), rabbit antibodies to parvalbumin 3 (1:3,000; Heller et al. 2002), rabbit antibodies to Pax2 (1:200; Covance, PRB-276B), monoclonal mouse antibodies to pan-cytokeratin (1:150; Sigma, C2562), monoclonal mouse antibodies to islet-1 (1:100; clone 40.3A4, cell culture supernatant; Developmental Hybridoma Bank, University of Iowa), monoclonal mouse antibody to BrdU (1:500; Sigma, B2531), and monoclonal rat antibody to uvomorulin/E-cadherin (1:2,000; Sigma, clone DECMA-1; U3254). Fluorescein isothiocyanate-, tetramethylrhodamine isothiocyanate-, or cyanine 5 (Cy5)-conjugated goat antirabbit, antimouse, antirat, and donkey-antiguinea pig secondary antibodies were used to detect primary antibodies. All secondary antibodies were multilabeling grade and purchased from Jackson Immunoresearch Laboratories (West Grove, PA, USA).

Immunocytochemistry and 5-bromo-2' -deoxyuridine labeling

The cultured cells were fixed with $4 \%$ paraformaldehyde (Electron Microscopy Sciences, Hatfield, PA, USA) in PBS ( $\mathrm{pH} 7.2$ ) for 15 min at room temperature. Nonspecific binding sites were blocked for $1 \mathrm{~h}$ at room temperature with $1 \%$ bovine serum albumin (BSA; $w$ / $v)$ and $5 \%(v / v)$ heat-inactivated goat serum in $0.1 \%$ Triton X-100 in PBS (PBT-1). The cells were then incubated overnight at $4^{\circ} \mathrm{C}$ with primary antibodies diluted in PBT-1. The following day, unbound antibodies were removed by three 15-min PBT-1 washes and one 15-min wash with PBT-2 (same as PBT-1 but without serum and $0.1 \%$ BSA). Fluorophore-conjugated secondary antibodies were used at a dilution of 1:200 in PBT-2. A 2-h incubation period at room temperature in the secondary antibody mixture preceded three washes for 15 min each in PBT-2. DAPI was used to visualize cell nuclei. BrdU (Sigma) was added at $9.8 \mu \mathrm{M}$ final concentration to the suspension culture during sphere formation to determine the incidence of S-phase entry. For BrdU antibody-labeling, cultures were treated with $2 \mathrm{~N} \mathrm{HCl}$ for 20 min after fixation. All primary antibodies were positively tested on native tissues (cryosections) as well as in control experiments, where they were omitted, which resulted in the absence of specific labeling in all cases.

\section{Apoptosis assay}

For the detection of apoptotic cells, sphere-derived cells were incubated with a fluorescent conjugate of annexin V (Annexin V-Cy5 Apoptosis Detection Kit, 
BioVision, CA, USA) for $5 \mathrm{~min}$ immediately after attachment to fibronectin-coated culture dishes and washed twice with annexin $\mathrm{V}$ binding buffer. After fixation with $4 \%$ paraformaldehyde, the cells were processed for coimmunolabeling with antibodies as described above.

\section{Microscopy and image processing}

The immunolabeled specimens were visualized with an epifluorescence microscope (Zeiss Axio Imager), photographed with a digital camera (AxioCam HR), and acquired with AxioVision 4.0 software running on a personal computer (Fujitsu-Siemens) running Windows XP. Fluorophores were color-coded using Adobe Photoshop (Version CS3, on a Macintosh computer running Mac OS X). This software was also used to adjust brightness, contrast, and dynamic range of some images. For the presentation of the timelapse image series of sphere transition (Fig. 6), the spheres were rotated to match their orientation in all images.

Representative spheres of each distinct morphologic phenotype were individually selected for scanning electron microscopy (SEM) using a micromanipulatorguided system (Eppendorf). Cells were fixed in 2\% glutaraldehyde $/ 4 \%$ paraformaldehyde in $0.1 \mathrm{M}$ sodium cacodylate buffer $(\mathrm{pH}$ 7.3) for $2-4 \mathrm{~h}$ followed by postfixation in $1 \%$ aqueous osmium tetroxide for $1 \mathrm{~h}$. Spheres were then dehydrated in a graded ethanol series (50-70-80-90-100\% ethanol, 20 min each), infiltrated for 30 min with $50 \%$ hexamethyldisilazane (HMDS) in ethanol, and chemically dried in 100\% HMDS (30 min). Spheres were subsequently mounted onto $12-\mathrm{mm}$ aluminum stubs with double-sided carbon-conductive tape and sputter-coated with a $100-\AA$ layer of $\mathrm{Au} / \mathrm{Pd}$ with a Denton Desk II Vacuum unit. Specimens were viewed with a Hitachi S-3400N variable pressure SEM operated under high vacuum at $5-10 \mathrm{kV}$ at a working distance of $7-10 \mathrm{~mm}$. Images $(2,560 \times 1,920$ pixels $)$ were captured with a CCD camera in TIF format. All chemicals were supplied by Electron Microscopy Sciences (EMS, Hatfield, PA, USA).

\section{Data analysis and statistics}

Presented are the mean values and standard deviations (SDs) of $n$ independent samples, unless indicated differently. Independent samples are defined as being obtained from individual animals. $P$ values were obtained with unpaired Student's $t$ tests. Differences were considered significant at a level of $P<0.05$ and are indicated in graphs and figure legends. Graphs were created using Citrin 1.2 software (Gigawiz).

\section{RESULTS}

Different sphere morphologies arise from neonatal cochlear sensory epithelium cell suspensions

For isolation of sphere-forming progenitor cells from cochlear sensory epithelia, we dissected the sensory epithelia of newborn (P1) mice (Fig. 1), enzymatically and mechanically separated the cells, and plated the resulting single cell suspension into nonadherent culture dishes. After 7 days in culture at a low cell density, we observed a heterogeneous population of morphologically distinct spheres (Fig. 2). We have previously shown that the vast majority of spheres that form in nonadherent low-density cultures are clonal, i.e., they were generated from single cells ( $\mathrm{Li}$ et al. 2003; Senn et al. 2007). Based on light microscopic criteria, we classified three distinct sphere types. (1) Solid spheres were the smallest with a diameter of $61.8 \pm 11.7 \mu \mathrm{m}(n=3,12$ spheres in total), they had a smooth defined edge, and were generally perfectly round (Fig. 2A, D). (2) Transitional spheres displayed solid and hollow regions (Fig. 2B, D) and were generally larger than solid spheres $(86.3 \pm 12.5 \mu \mathrm{m}$ in diameter, $n=3,12$ spheres in total). (3) Finally, hollow spheres had a thin, translucent hull and an average diameter of $150.8 \pm 64.6 \mu \mathrm{m}(n=3,12$ spheres in total; Fig. 2C, D). Hollow spheres appeared more buoyant than the other two sphere types and the surface of these spheres displayed large and polygon-shaped cells (Fig. 2C, D).

To characterize the morphological properties of the three sphere types in more detail, we individually collected representative spheres of each type and imaged their surface morphology with a SEM. We were particularly interested in the appearance of solid spheres because the light microscope revealed very little surface structure or cellular organization (Fig. 2A, D). The SEM revealed that solid round spheres consist of densely packed small cells (Fig. 3A, B). Transitional spheres were more irregularly shaped and displayed a smoother surface than the solid spheres (Fig. 3C, D). Hollow spheres (Fig. 3E-H) were more difficult to image because they often collapsed partially, likely a result of their fragile single cell layer organization, which was revealed when the spheres were ruptured during SEM sample processing (Fig. 3G, H). The walls of this sphere type were formed by a single layer of flat cells and the hollow spheres' lumina were generally devoid of cells.

The different sphere types emerge at different time points

Occurrence of a mixed population of spheres after 7 days in culture raised our interest whether the different morphologies are already observable at the 

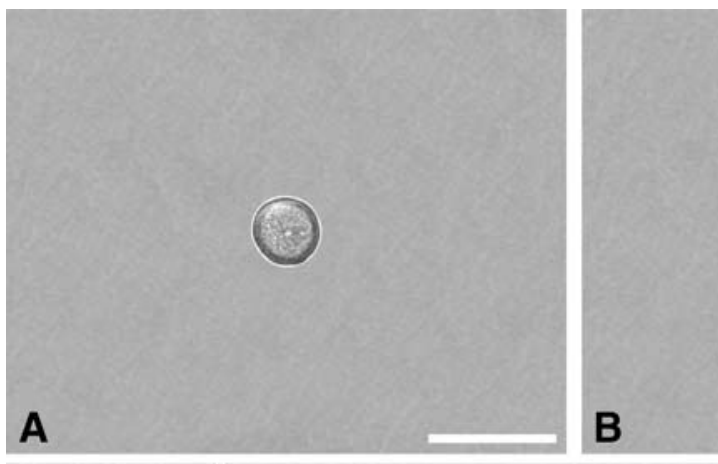

B

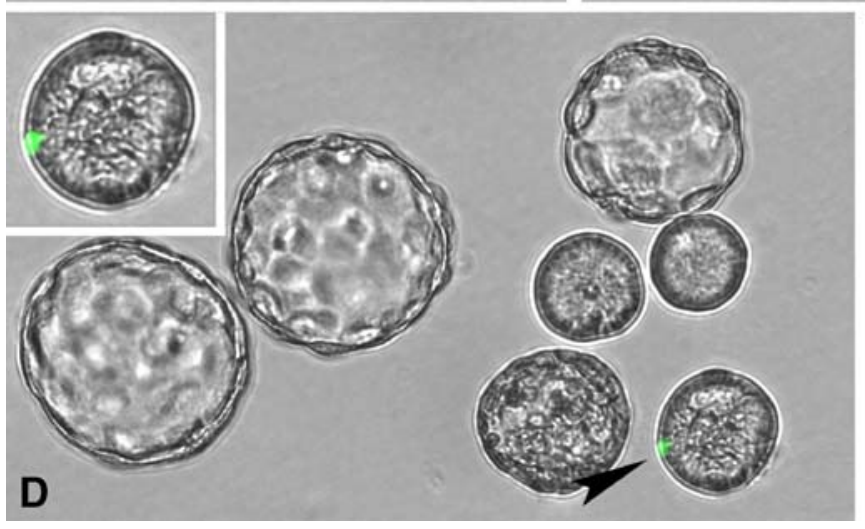

FIG. 2. Morphology of spheres isolated from the early postnatal murine cochlear sensory epithelium. A Solid sphere that is characterized by a round shape and a regular, smooth rim. B Transitional sphere that displays solid and hollow regions. C Buoyant hollow sphere that is characterized by a surface composed of large polygon-shaped cells.

early stages of sphere formation. Spheres can already be distinguished after 2 days in culture, and we hypothesized that, if the different spheres arise in parallel from distinct proliferative progenitor cells, they should be detectable at comparable ratios at early, intermediate, and late time points. We analyzed the composition of suspension cultures after 2, 4, 7, and 12 days (Fig. 4). We found that, after 2 days in culture, the majority $(75.4 \pm 13.9 \%)$ of spheres were solid, $23.5 \pm 6.1 \%$ of spheres had transitional morphology, and only $1.1 \pm 0.4 \%$ of the spheres were hollow. On day $4,43.7 \pm 5.7 \%$ of the spheres were solid, $46.6 \pm 6.2 \%$ were transitional, and $9.7 \pm 2.2 \%$ displayed hollow morphology. After 7 days, the percentage of solid spheres declined to $16.8 \pm 4.1 \%$, transitional spheres posted the largest pool $(47.3 \pm 8.3 \%)$, and the percentage of hollow spheres increased to $35.9 \pm 5.5 \%$. After 12 days, we counted $7.1 \pm 2.9 \%$ solid spheres, $30.4 \pm 5 \%$ transitional spheres, and $62.5 \pm 6.1 \%$ hollow spheres.

\section{Dividing cells give rise to all three sphere types}

One of the defining features of somatic sphereforming stem/progenitor cells is their proliferative capacity. To assess whether the different sphere types displayed different potential to undergo S-phase, we

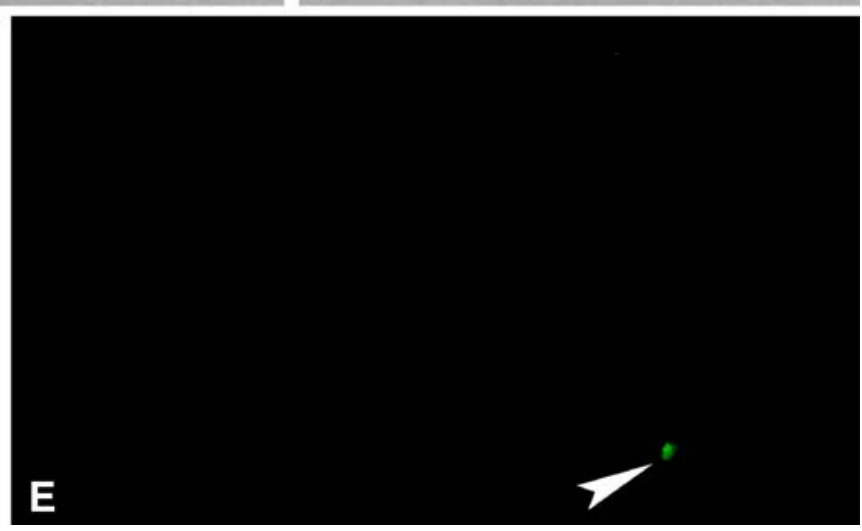

D Example of sphere compositions after 7 days suspension culture. Very infrequently, nGFP-positive cells were found in spheres (arrowhead; inset and E). These spheres were excluded from experiments aimed at studying hair cell differentiation in vitro. Scale bar $=100 \mu \mathrm{m}$ for A-C; $75 \mu \mathrm{m}$ for $\mathbf{D}$ and $\mathbf{E}$.

determined the percentage of sphere cells that incorporated BrdU during the first 4 days in culture. We picked this time point because it is the first early time point at which all three sphere types can be consistently obtained. After 4 days in culture, the spheres were attached to fibronectin-coated dishes, fixed, and BrdU incorporation was determined by immunocytochemistry. We found that all three sphere types displayed high numbers of cells that had synthesized nuclear DNA ranging from $93 \pm 4.2 \%$ (solid spheres) to $87.7 \pm 2.6 \%$ (hollow spheres) (Fig. 5). In each sphere, we found different intensities of nuclear immunoreactivity for incorporated BrdU - a finding that might reflect the dynamics of cell proliferation in a heterogeneous sphere cell population where some cells cycle faster, which is associated with repeated incorporation of BrdU, whereas other cells do exit the cell cycle after a relatively short period of proliferation.

Based on the BrdU incorporation experiments, we conclude that all three sphere types are formed from neonatal cochlear sensory epithelium cells that have high proliferative capacity. It has been previously demonstrated that utricular and cochlear sensory epithelium-derived spheres arise from individual cells (Li et al. 2003; Senn et al. 2007), which supports the 

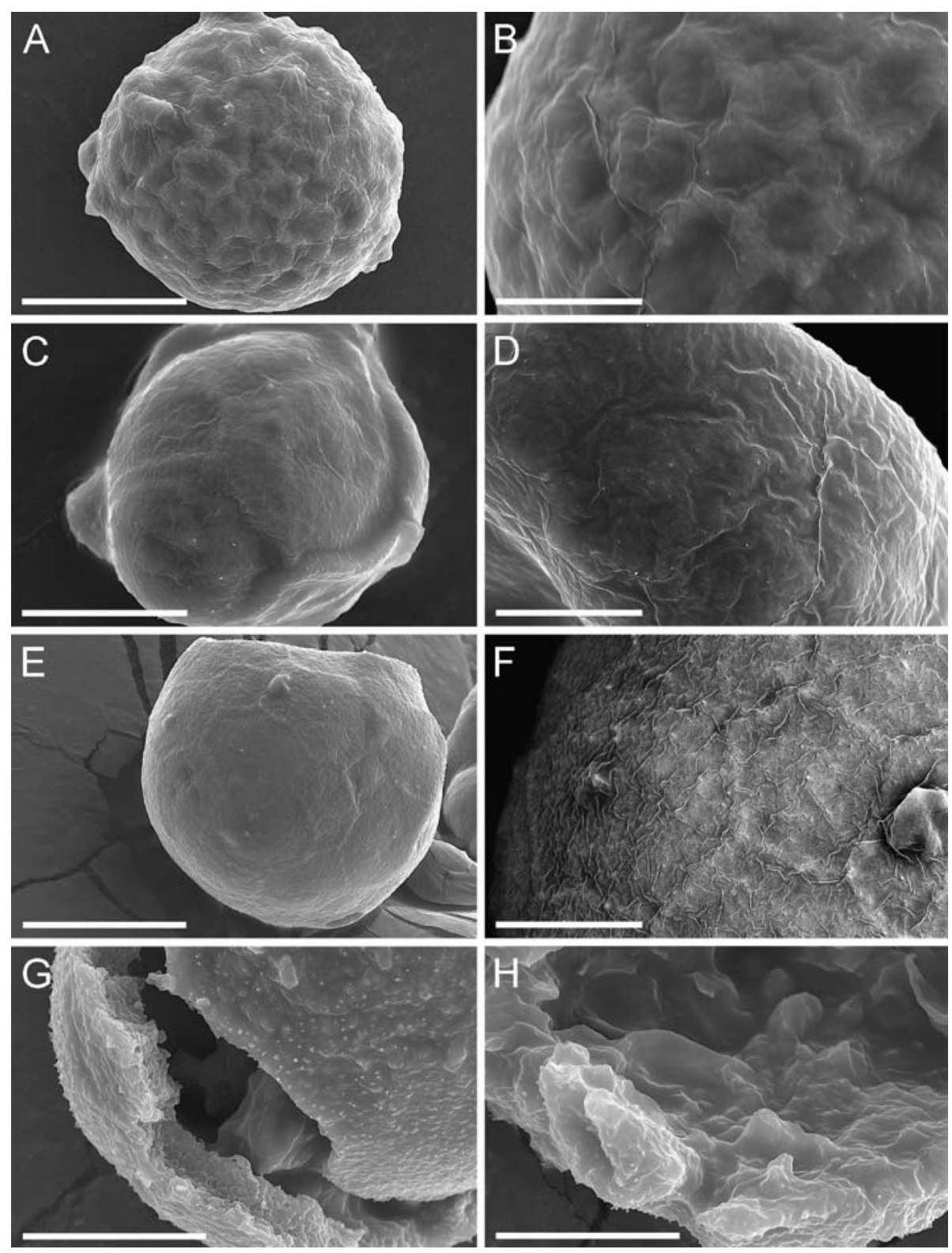

FIG. 3. SEM images of distinct sphere types. A A solid sphere appears to be formed by densely packed cells. B High magnification of the sphere

shown in $\mathbf{E}$ reveals the polygonal shape of the large cells that form this sphere type. G This hollow sphere was ruptured during processing for SEM, which revealed that the wall of this sphere type is composed of a single layer of flat cells. $\mathbf{H}$ The lumen of a ruptured hollow sphere appears to be devoid of cellular structures. Scale bar $=40 \mu \mathrm{m}$ for $\mathbf{E}, 30 \mu \mathrm{m}$ for $\mathbf{A}$ and more irregular. D High magnification of the surface of a transitional sphere. E Hollow sphere that represents the sphere type with the most mature epithelial surface morphology. F High magnification of the sphere

C, and $10 \mu \mathrm{m}$ for $\mathbf{B}, \mathbf{D}, \mathbf{F}, \mathbf{G}$, and $\mathbf{H}$.

conclusion that all three sphere types arise from proliferating individual cells.

\section{Hollow spheres emerge from solid spheres}

The epithelial morphology of hollow spheres raised the possibility that these spheres are the progeny of proliferative epithelial cells, whereas the solid spheres could arise from a different cell population with less defined epithelial features. To test for this possibility, we decided to observe individual spheres over a period of time. When we collected individual solid, transitional, and hollow spheres from 7-day-old cultures and maintained the individual spheres for an additional 7 days, we found that all spheres acquired a hollow morphology at the end of the culture period. This observation suggested that hollow spheres arose from solid and transitional spheres. We next collected 20 solid spheres that formed after 3 days in culture, and we followed each individual sphere for 6 days, taking pictures every $24 \mathrm{~h}$ (Fig. 6). In all cases, we found that solid spheres developed hollow spaces and that these hollow spaces 


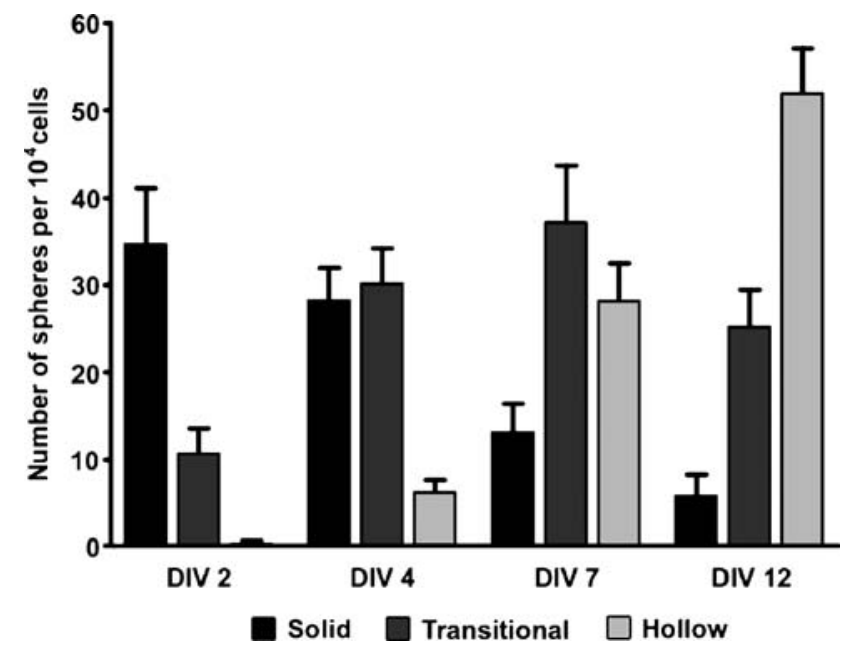

FIG. 4. Quantification of different sphere morphologies after 2, 4, 7 , and 12 days in suspension culture. Shown is the number of primary spheres per $10^{4}$ plated single cells from cochlear sensory epithelia that formed in serum-free suspension culture in nonadherent Petri dishes. The predominantly solid sphere population observed after 2 days is shifted toward a predominantly transitional and hollow sphere population after 7 and 12 DIV. Shown are the mean numbers of spheres obtained in three independent experiments. Error bars indicate standard deviation.

enlarged consecutively until after 6 days, the spheres were completely transformed into hollow spheres.

Hollow spheres consist of epithelial cells that lose the ability for self-renewal

The observation that small solid spheres undergo a morphological transformation into large hollow spheres led us to investigate if the sphere types vary in their expression of E-cadherin, a prominent component of the adherens junctions in many mature epithelial cells. In all three sphere types, we detected expression of E-cadherin but the intensity and the subcellular distribution of the immunoreactivity was distinct. We detected low expression of E-cadherin associated with plasma membrane and intracellular structures in the small cells of solid spheres (Fig. 7A, B). The large, polygonal cells of hollow spheres, in contrast, showed prominent expression of E-cadherin associated with cell junctions (Fig. 7C, D).

Increased supporting cell specialization and maturation has been associated with upregulation or subcellular redistribution of E-cadherin (Whitlon 1993). Likewise, decreased capacity for sphere formation (or loss of stemness) in maturing neonatal auditory sensory epithelia has been hypothesized to be a function of increased cytomorphological specialization of cochlear supporting cells (Oshima et al. 2007).

To investigate if the distinct sphere types that form from cochlear sensory epithelium-derived progenitor cells have the ability to self-renew, we mechanically dissociated solid, transitional, and hollow spheres and cultured the sphere-derived cells under the same conditions that had been used to generate primary spheres. Only solid and transitional spheres had the capacity to consistently give rise to new generations of spheres, whereas hollow spheres could not be successfully propagated (Fig. 8). This result suggests a decline in the ability for secondary sphere formation during the transition from solid to hollow spheres. Because the sphere formation assay is directly testing self-renewal and propagation, we conclude that the majority of hollow spheres have lost sphere-forming stem cells, or alternatively, that hollow sphere cells for the most part have lost their stemness or competence for self-renewal.

\section{Proliferative spheres contain newly generated otic progenitors}

Pax-2 is a paired-box transcription factor that plays a critical role in inner ear development and is expressed in the otic placode as well as in nascent sensory epithelia, where its expression correlates with otic progenitor cell proliferation ( $\mathrm{Li}$ et al. 2004a; Nornes et al. 1990; Torres et al. 1996). Spheres grown from utricle-derived stem/progenitor cells express Pax-2 (Li et al. 2003; Martinez-Monedero et al. 2008), indicating that a subpopulation of sphere cells expresses placodal markers. To investigate Pax-2 expression in cochlear sensory epithelium-derived spheres, we used polyclonal antibodies to Pax-2 protein and we quantified Pax-2 expression among solid, transitional, and hollow spheres. We found that a small subset of sphere cells expressed Pax-2 (Fig. 9A-C). In 3-day-old solid spheres, 2.6 $\pm 1.2 \%$ of the sphere cells were immunoreactive for Pax-2, whereas the number of Pax-2-positive cells in transitional spheres, harvested after 5 DIV, was $1.3 \pm 0.75 \%$; 7 DIV hollow spheres harbored only $0.65 \pm 0.29 \%$ Pax2-positive cells. These results are consistent with the notion that solid spheres seem to contain the highest number of presumptive otic progenitor cells, which are presumably able to differentiate into sensory epithelium cell types, including hair cells. Likewise, the larger fraction of Pax-2-positive cells in solid spheres appears to correlate with their propagation potential or self-renewal ability, whereas the decline in Pax-2-expressing cells in hollow spheres seems to accompany reduced ability for further propagation. Nevertheless, it is unclear whether and probably unlikely that the Pax-2positive sphere cells are the sphere-forming stem cells (also see the "Discussion" section).

To investigate whether cell death is responsible for the decline of Pax-2-positive cells during sphere transition, we used annexin $\mathrm{V}$ labeling to detect 


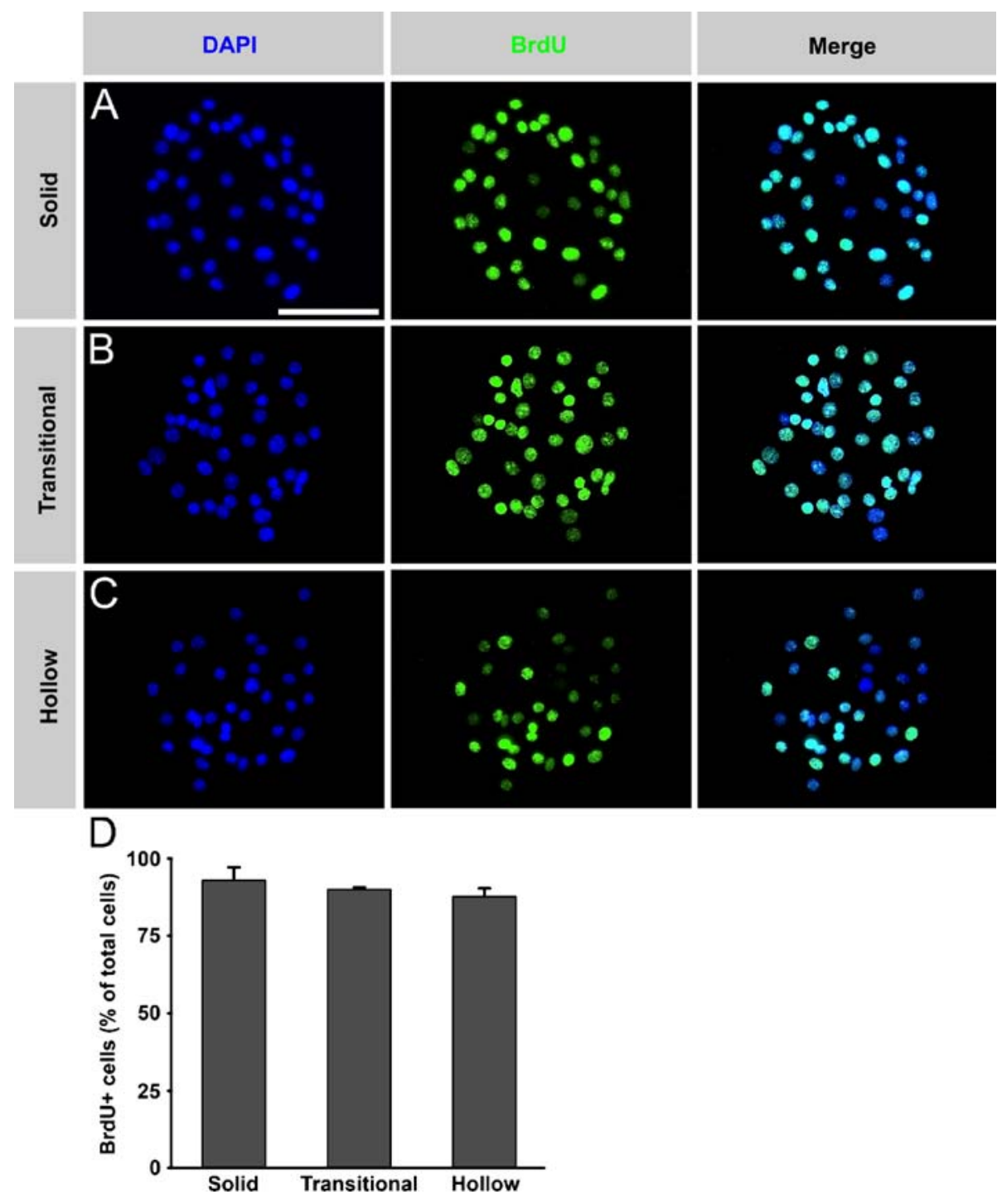

FIG. 5. BrdU uptake during sphere formation. A-C Typical cochlear sensory epithelium-derived spheres generated after 4 days in suspension culture in the presence of BrdU. In most spheres, all cells were immunoreactive for BrdU (green). D Almost all cells in each 4-day-old

apoptotic cells (Martin et al. 1995). Overall, we found a low number of apoptotic cells, ranging from $0.68 \pm$ $0.39 \%$ in solid spheres to $0.55 \pm 0.26 \%$ in transitional spheres and $0.26 \% \pm 0.12 \%$ in hollow spheres. Using the annexin $\mathrm{V}$ assay, we detected no apoptotic cell (out of several hundreds in total) that was positive for Pax-2 (Fig. 9D). We conclude that apoptosis does not play a significant role in the observed reduction of Pax-2-expressing cells.

A distinguishing feature of dividing otic progenitor cells is Pax-2 expression ( $\mathrm{Li}$ et al. 2004a), and we consequently sought to determine whether Pax-2positive cells in spheres were (1) generated from dividing cells and (2) whether the Pax-2-expressing cells were actively cycling. We found that $100 \%$ of the Pax-2-positive cells that were detectable in 3-day-old sphere type were immunoreactive for BrdU incorporation ( $n=6$, with 20 spheres analyzed per experiment). Error bars indicate standard deviation. Nuclei are visualized with DAPI (b/ue). Scale bar $=100 \mu \mathrm{m}$.

solid spheres were generated from cells that went through the S-phase during sphere formation, which is not surprising, because nearly all cells in the spheres were BrdU-positive (Fig. 5). When we added BrdU to 66-h-old sphere cultures and incubated for an additional $6 \mathrm{~h}$ in the presence of BrdU, we found that a subset $(31.8 \pm 7.5 \%)$ of Pax-2-positive cells had incorporated BrdU. Conversely, only $19 \pm 4.5 \%$ of the Pax-2-negative cell population had incorporated BrdU during the 6 -h pulse ( $n=6$, with 25 spheres analyzed per experiment). These results show that solid spheres contain actively cycling Pax-2-expressing cells and that these cells appear to cycle faster than the other sphere cells.

Another marker protein that is expressed in the developing inner ear is islet-1, a LIM/homeodomain transcriptional regulator. It has been recently demon- 

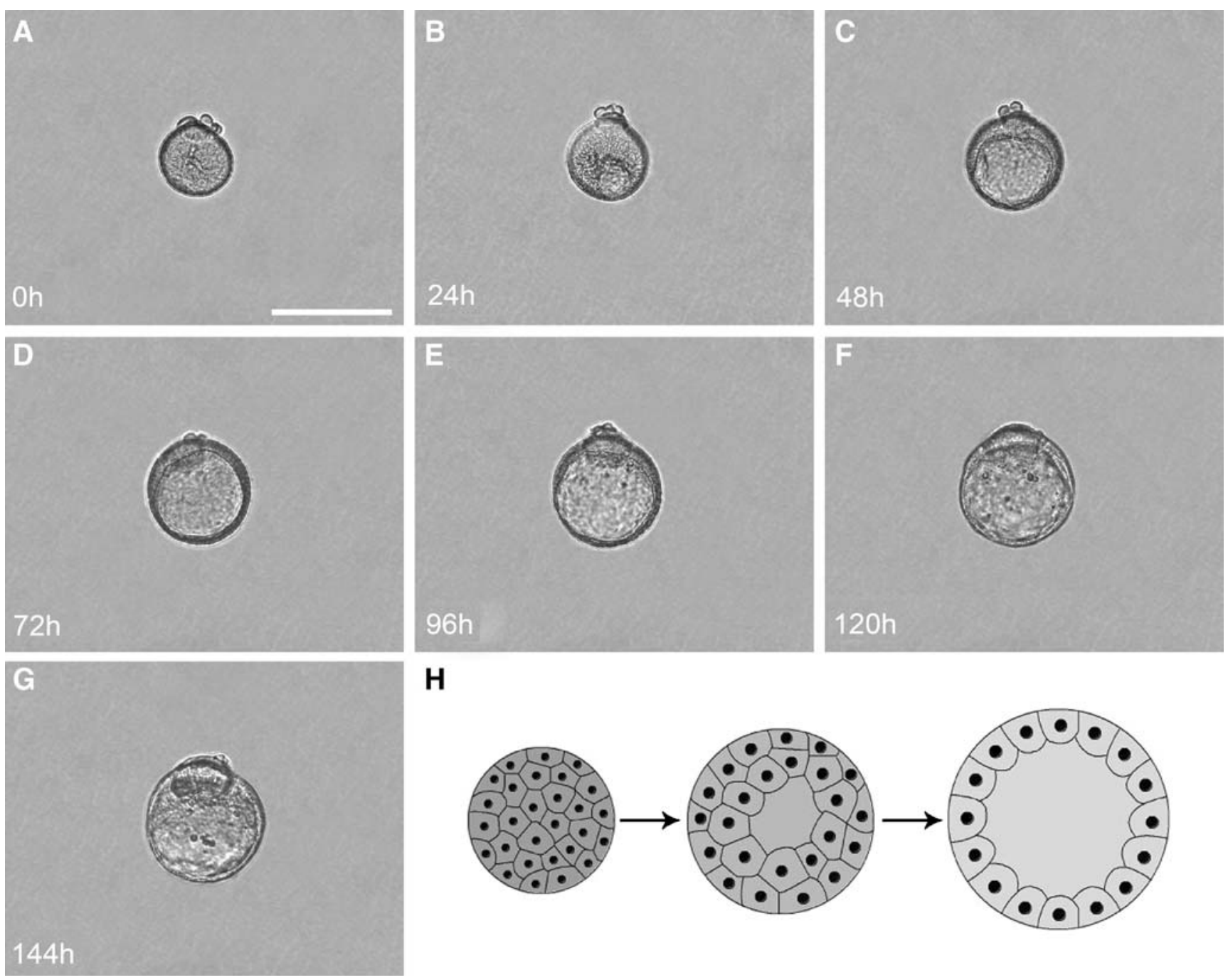

H

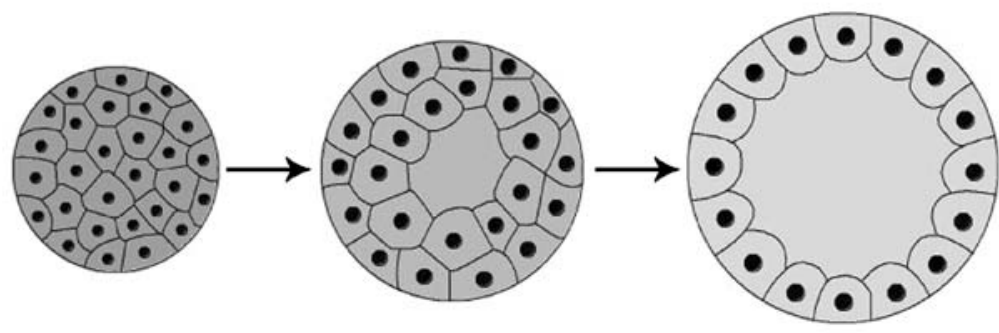

FIG. 6. Sphere transformation. A-G A solid sphere that was generated after 3 days in suspension culture (A) develops an increasingly larger hollow space (B-F) and finally attains the stage of a hollow sphere with a wall composed by a single cell layer $(\mathbf{G})$. We deliberately selected a "blotched" small solid sphere with a few

strated that islet-1 is an early marker of the differentiating inner ear sensory epithelia, where its upregulation in the presumptive nascent hair and supporting cells is accompanied by downregulation of Pax-2 (Huang et al. 2008; Li et al. 2004b). A substantial fraction of the sphere cells expressed islet-1, indicating that this transcription factor appears to be a useful marker and potential indicator of the progenitor cell status of these cell populations (Fig. 10). In solid spheres, $62.9 \pm 14.9 \%$ of the sphere cells expressed islet-1. Considerably lower numbers of islet-1-expressing cells were observed in transitional spheres $(45.9 \pm 15.2 \%)$, and significantly

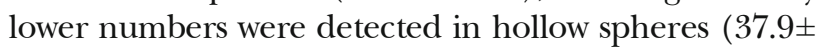
$8.8 \%$ ) (Fig. 10C). Double immunolabeling for islet-1 and Pax-2 showed that only a subset $(21 \pm 8.4 \%)$ of Pax-2positive cells coexpressed islet-1 (Fig. 10D). This observation is consistent with the previously reported anti- loosely attached cells to indicate that the transformation of the same sphere was followed over a period of $144 \mathrm{~h}$. All 20 selected spheres underwent the transition shown in the time-lapse images. Scale bar= $100 \mu \mathrm{m}$. H Schematic drawing of the morphological transformation of a solid into a hollow sphere, via a transitional morphology.

dromic expression dynamics of these two markers in the developing sensory epithelia of the inner ear $(\mathrm{Li}$ et al. 2004b).

\section{Differentiation of mature inner ear cell types}

The differential expression of the otic progenitor cell markers Pax-2 and islet-1 in cells of the distinct sphere types led us to explore whether these spheres vary in their capacity to generate mature inner ear cell types in vitro. We individually collected spheres of each type and cultured them in fibronectin-coated dishes for 2 weeks in serum-free medium with defined medium supplements in the absence of added growth factors. These culture conditions are sufficient to induce sphere attachment and spontaneous differentiation of sphere cells into mature cell types (Li et al. 2003; 

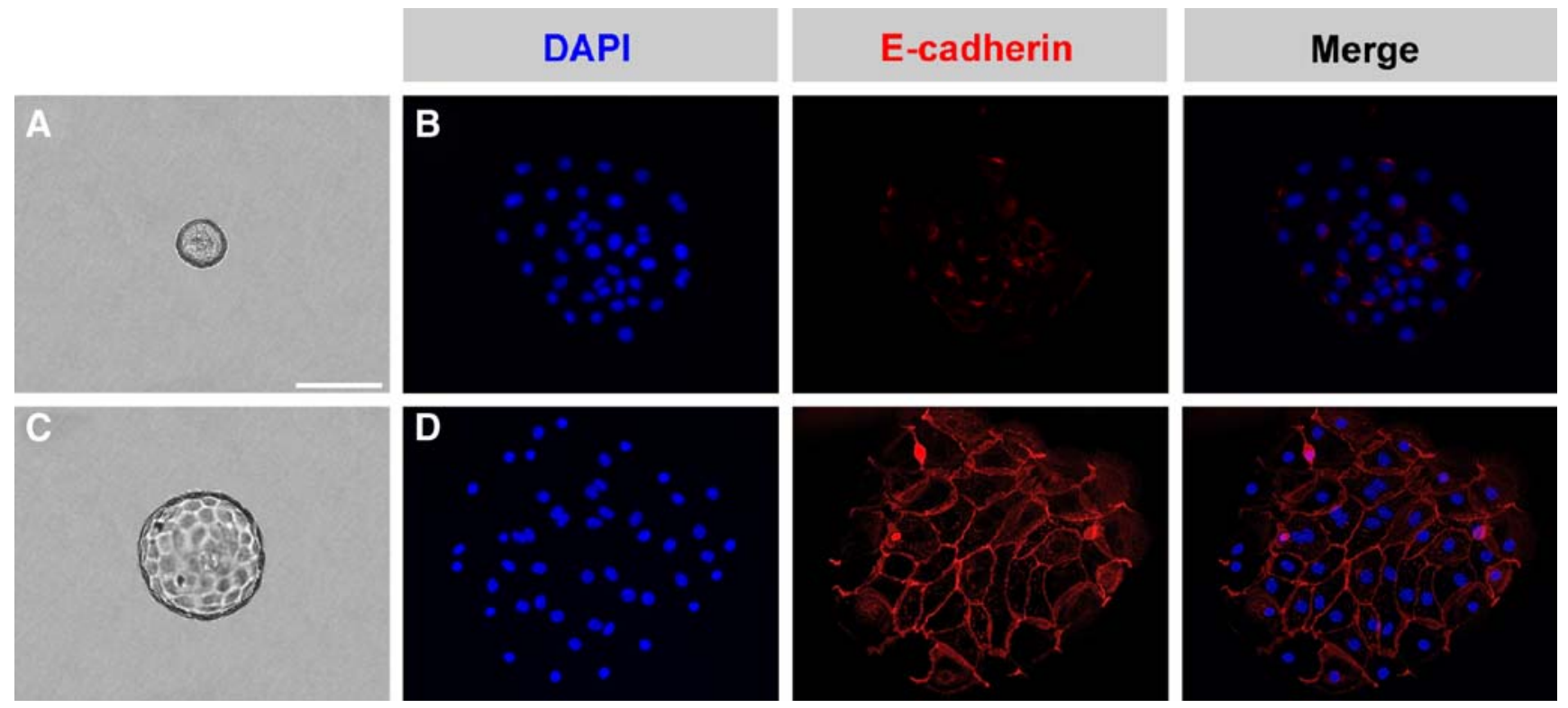

FIG. 7. Expression of E-cadherin in sphere cells. A Typical solid sphere, B after attachment shows low E-cadherin (red) expression. C A typical hollow sphere, D after attachment shows increased levels of the membrane-associated glycoprotein E-cadherin. E-cadherin is localized to cellular junctions, indicative of mature epithelial mor-

phology. Spheres in B and D were transferred to fibronectin-coated plates and immunostained immediately after attachment. Cell nuclei are visualized with DAPI staining (b/ue). Scale bar $=100 \mu \mathrm{m}$ for $\mathbf{A}, \mathbf{C}$, and $\mathbf{D}$ and $50 \mu \mathrm{m}$ for $\mathbf{B}$.
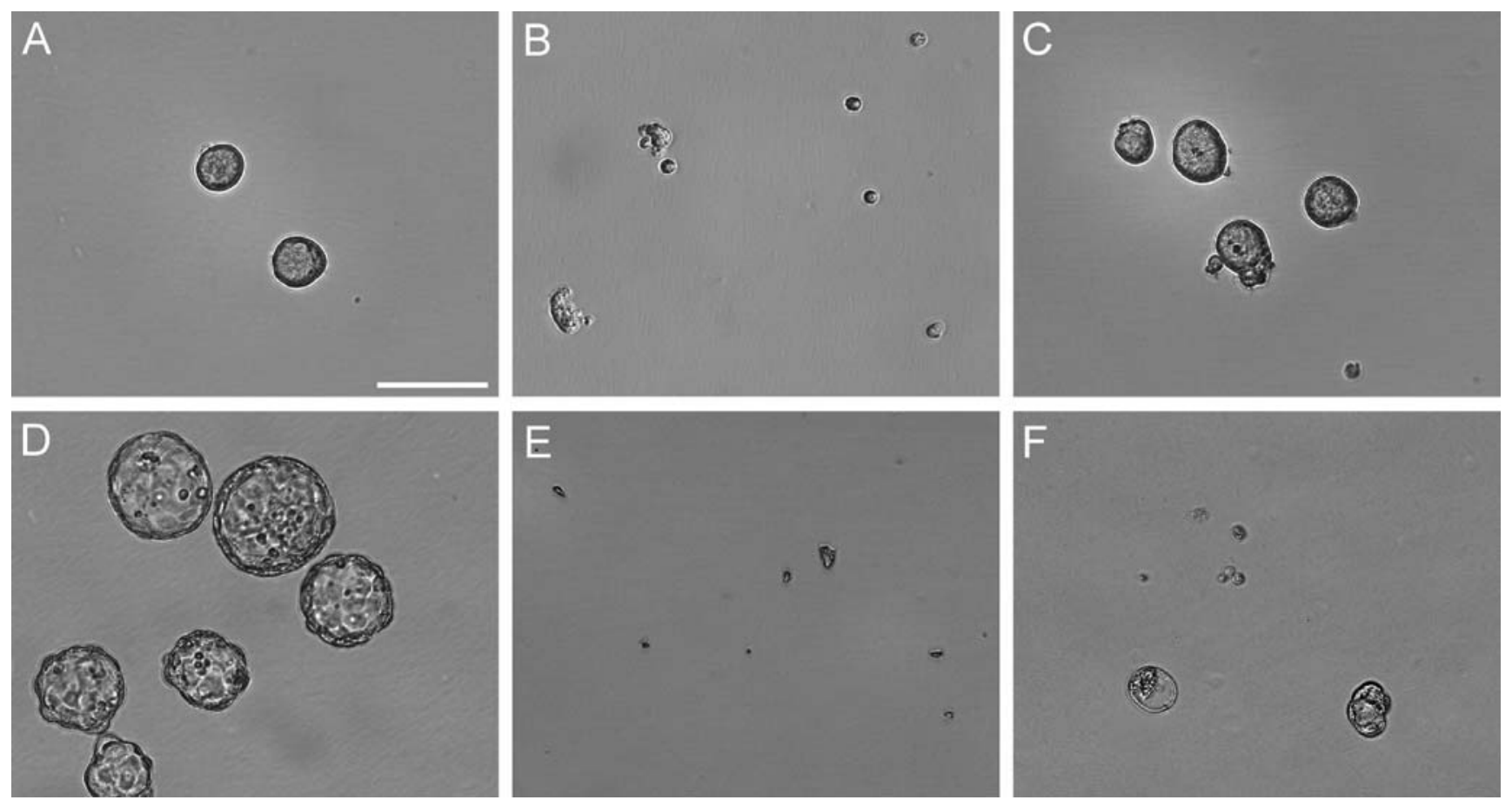

FIG. 8. Sphere types vary in their capacity for self-renewal. A-C Solid spheres (A), which were mechanically dissociated (B), consistently formed new generations of spheres after 3 days $(\mathbf{C})$. Mechanical dissociation resulted in single cells and some sphere fragments. Overall, sphere numbers consistently increased by 1.5-2-fold, when propagating solid spheres. D-F Hollow spheres (D) were mechanically

dissociated (E) and cultured for 3 days (F). Mechanical dissociation of hollow spheres resulted in single cells and small epithelial tissue fragments (E). Even prolonged culture for 7 days only occasionally led to growth of new spheres and structures with hollow or disorganized morphology. Sphere numbers decreased when propagating hollow spheres. Scale bar $=100 \mu \mathrm{m}$. 


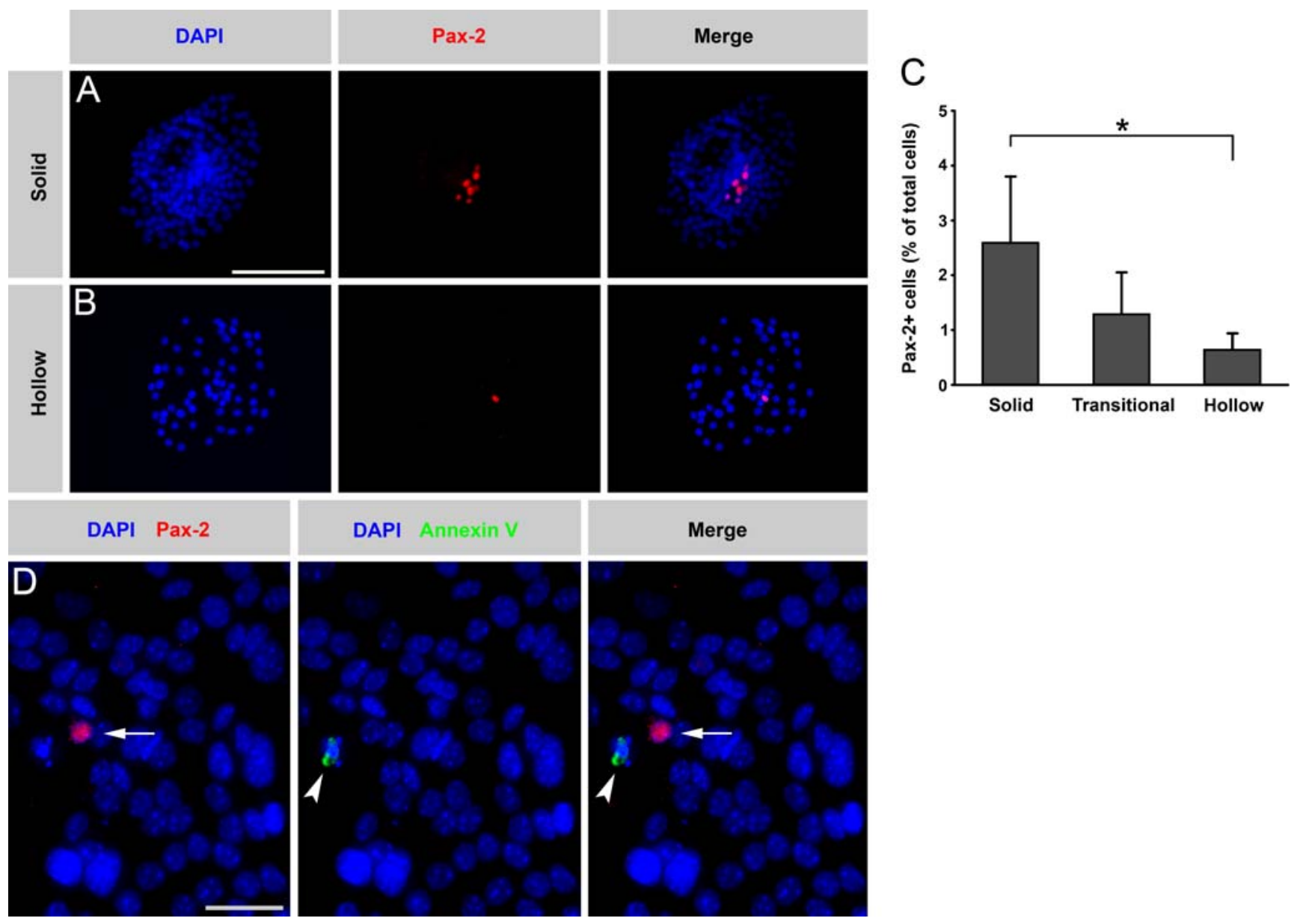

FIG. 9. Pax-2 expression in sphere cells. A and B Nuclear Pax-2immunoreactivity (red) is detectable in a subset of sphere cells. Typically, Pax-2-expressing cells were found to be clustered in patches. Scale bar $=100 \mu \mathrm{m}$. C Solid spheres contained significantly more Pax-2-expressing cells than hollow spheres $(n=6$, with 25 spheres analyzed per experiment). ${ }^{*} P<0.01$. Error bars indicate standard deviation. D Apoptosis in sphere cells excludes Pax-2expressing cells. Shown is annexin V labeling (arrowhead, green) and immunostaining for Pax-2 (arrow) in transitional sphere-derived cells. In six independent experiments with 25 spheres per experiment, we did not observe a single Pax-2-positive cell that was also stained with annexin V. Scale bar $=25 \mu \mathrm{m}$. Nuclei are visualized with DAPI (blue).
Oshima et al. 2007; Savary et al. 2007, 2008; Senn et al. 2007). To identify differentiated cells, we used antibodies specific for the early hair cell markers myosin VIIa (Oshima et al. 2007) and parvalbumin 3 (Heller et al. 2002), as well as antibodies to pan-cytokeratin, which label epithelial cells including supporting cells (Lawlor et al. 1999; Li et al. 2003; Zheng et al. 1997). The morphology and the pattern of immunoreactivity for pan-cytokeratin after 5 days (Fig. 11A, B) and after 14 DIV (Fig. 11C, D) suggested a substantial maturation of the cells. We examined cultures from solid, transitional, and hollow spheres and we found that the cell populations derived from all three sphere types had a similar capacity to generate epithelial supporting cell-like cells (Fig. 11E). To study the differentiation of nascent hair cells in sphere-derived cultures, we used Math-1/nGFP transgenic reporter mice that express a nuclear version of enhanced green fluorescent protein (nGFP) under the control of an Atoh1 gene enhancer (Lumpkin et al. 2003). We rarely observed nGFP-positive cells in the floating spheres (Fig. 2D, E). For quantitative comparison of hair cell differentiation, we collected nGFP-negative spheres of each type. We further ensured absence of nGFP-positive cells immediately after attachment of the spheres and only cultures devoid of nGFP-positive cells were used to quantify hair cell differentiation. With this experimental regimen, nGFP-positive cell nuclei were detectable 3 days after sphere attachment and withdrawal of growth factors. The number of nGFPpositive cells further increased during the culture period and after 14 days of differentiation, we analyzed the cultures by immunocytochemistry for expression of hair cell markers (Fig. 12). All three sphere types analyzed had the capacity to generate mature hair cells. The highest number of $\mathrm{nGFP} /$ myosin VIIa/parvalbumin 3 


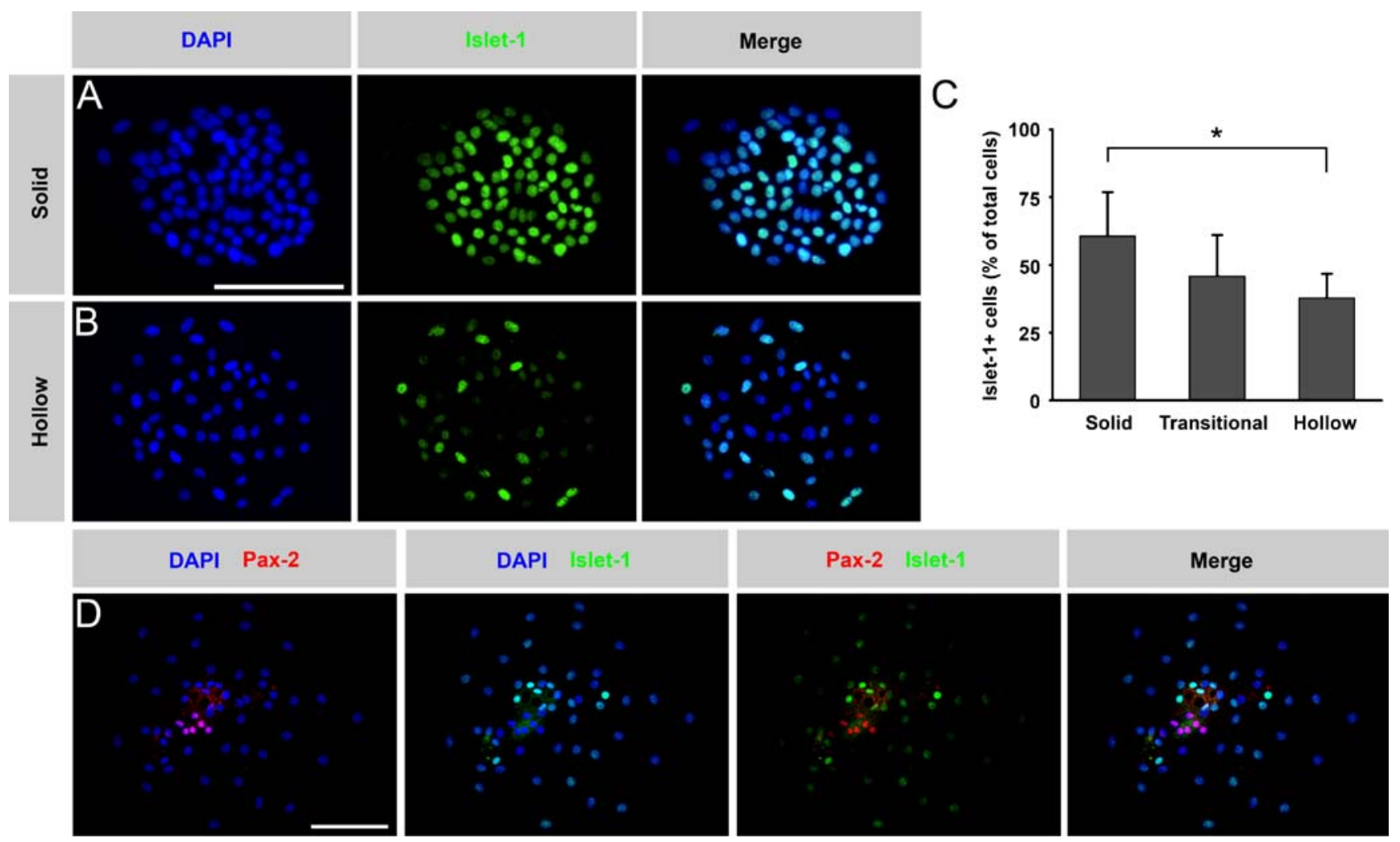

FIG. 10. Expression of islet-1 in sphere cells. A and B Nuclear islet-1 immunoreactivity (green) can be observed in all sphere types. C Solid spheres harbored the highest number of islet-1-expressing cells and the immunopositive cells typically showed a more intense immunoreactivity for islet- 1 than those in transitional and hollow spheres $(n=$ 6 , with 25 spheres analyzed per experiment). ${ }^{*} P<0.01$. Scale bar $=$

triple-positive cells $(0.29 \pm 0.08 \% ; n=8)$ was detectable in cell populations derived from solid spheres (Fig. 12B). Cell populations derived from transitional and hollow spheres harbored significantly less nGFP/myosin VIIa/ parvalbumin 3 triple-positive cells. In sphere-derived cell populations, $84 \%$ of all nGFP-positive cells coexpressed the hair cell markers myosin VIIa and parvalbumin 3 after a 14-day differentiation period, suggesting that these cells had acquired a hair cell-like phenotype. We speculate that the subset of nGFP-positive cells that did not express other hair cell markers are more nascent hair cell-like cells, although we cannot exclude that these cells develop along a different developmental pathway. In parallel, we coimmunolabeled differentiated cultures for hair cell and supporting cell markers and we found that myosin VIIa-positive and pan-cytokeratin-positive cells were well-organized in differentiating colonies and expression of these phenotypic markers was mutually exclusive (Fig. 12C). Finally, we tested whether hair celllike cells were generated from proliferating progenitors by adding BrdU for a 48-h period during sphere formation. After a 14-day differentiation period, we found BrdU-positive cells that coexpressed the hair cell markers myosin VIIa and parvalbumin 3, indicating that
$100 \mu \mathrm{m}$. D Expression of islet-1 and Pax-2 (red) in sphere cells. Shown is a representative example of the expression pattern of both otic progenitor cell markers in a transitional sphere. A minority $(21 \%)$ of Pax-2-expressing sphere cells coexpressed islet-1 ( $n=6$, with 25 spheres analyzed per experiment). Nuclei are visualized with DAPI (blue). Scale bar $=100 \mu \mathrm{m}$.

hair cell-like cells arose from sphere cells that went through the synthesis phase of the cell cycle during sphere formation (Fig. 13).

\section{DISCUSSION}

We hypothesize that lost sensory hair cells are replaced in most metazoans throughout life and that the replacement mechanisms are generally stem cellbased. In vertebrates, replacement has been described for hair cells that are lost in response to trauma, as seen in birds (Corwin and Cotanche 1988; Cotanche 1987; Ryals and Rubel 1988), due to natural turnover, for example, in the lateral line of zebrafish (LopezSchier and Hudspeth 2006), or due to continual growth, such as in the inner ear of sharks (Corwin 1981). In regenerating hair cell-bearing organs, supporting cells evidently serve as bona fide self-renewing somatic stem cells. In the basilar papilla of birds, for example, supporting cells have the ability to divide asymmetrically, thereby generating new hair cells as well as identical copies of themselves. Likewise, symmetrically dividing supporting cells that replenish the pool of 

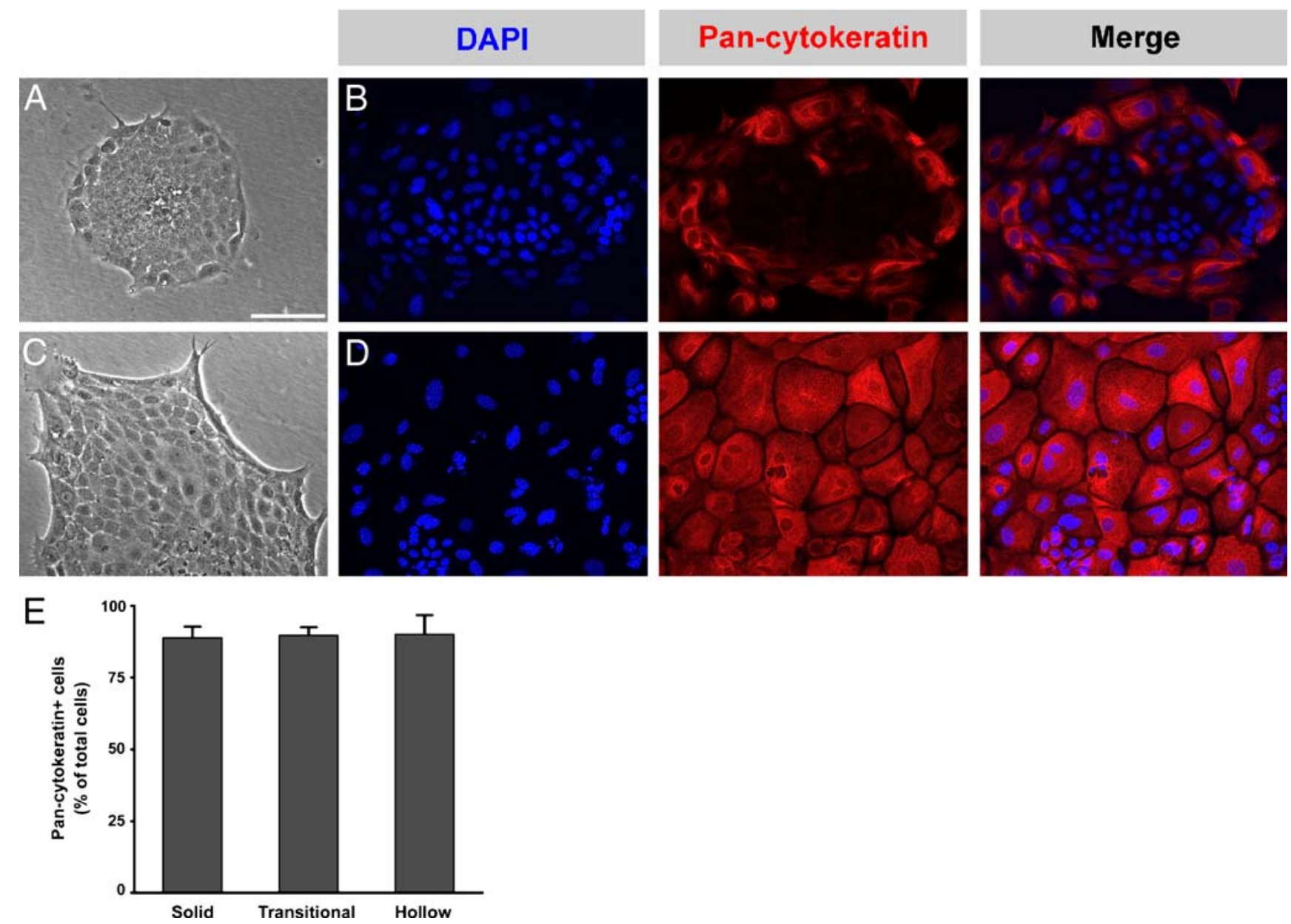

FIG. 11. Differentiation of cochlear sensory epithelium-derived sphere cell populations into supporting cell-like cells. A Shown is a typical colony generated after attaching a solid sphere and 5 days of differentiation. B After 5 days of differentiation, supporting cell-like cells that were immunopositive for pan-cytokeratin (red) were detectable in a colony derived from a solid sphere. Differentiation started in the periphery of this colony where the cells adopted characteristics of maturing epithelial cells demonstrating a polygonal morphology and robust expression of pan-cytokeratin. In contrast, cells in the center of the colony appeared denser and the cells did not

supporting cells, which replace lost hair cells by phenotypic conversion, are also fulfilling the definition for somatic stem cells because they self-renew. In birds, this regenerative ability is maintained throughout the life of the animal, resulting in maintenance of auditory thresholds, even in very old specimens (Langemann et al. 1999). In mammals, however, sensory hair cell regeneration is severely hampered. As a result of this loss of regenerative capacity, cochlear hair cells do not regenerate and vestibular hair cells regenerate only at a very low level (Forge et al. 1993; Warchol et al. 1993). Using a sphere-generation assay, it has been shown that the adult vestibular system harbors few, but clearly demonstrable, self-renewing stem cells, which could account for the weak regenerative capacity of the adult vestibular sensory epithelia ( $\mathrm{Li}$ et al. 2003). Although express this epithelial cell marker. C After 14 days of differentiation, the solid sphere-derived colony has expanded when compared to 5day-old colonies (A). D The majority of the cells show a mature cubical shape and prominent expression of pan-cytokeratin (red). Nuclei are visualized with DAPI staining (b/ue). Scale bar $=100 \mu \mathrm{m}$ for $\mathbf{A}$ and $\mathbf{C}$ and $50 \mu \mathrm{m}$ for $\mathbf{B}$ and $\mathbf{D}$. E After 14 days of differentiation, a similar percentage of pan-cytokeratin-positive cells was found in cell populations derived from solid, transitional, and hollow spheres (shown are the mean numbers $\pm \mathrm{SD}$ of four independent experiments, 20 spheres each).

the adult mammalian cochlea does not appear to contain cells with stem cell features, it was surprising that neonatal cochlear sensory epithelial cells have the ability to generate self-renewing floating clonal colonies (spheres), which give rise to hair cell-like cells after a differentiation period in adherent culture conditions (Oshima et al. 2007). In mice, this proliferative ability of some supporting cells sharply declines during the first two neonatal weeks, and cochlear cells with proliferative capacity cannot be isolated from animals 3 weeks or older (Oshima et al. 2007; White et al. 2006).

Several laboratories have described sphere formation from cultured neonatal cochlear or vestibular cells, and we noticed a substantial variation of sphere morphology among recent reports, including our own (Li et al. 2003; Oshima et al. 2007; Savary et al. 2007, 


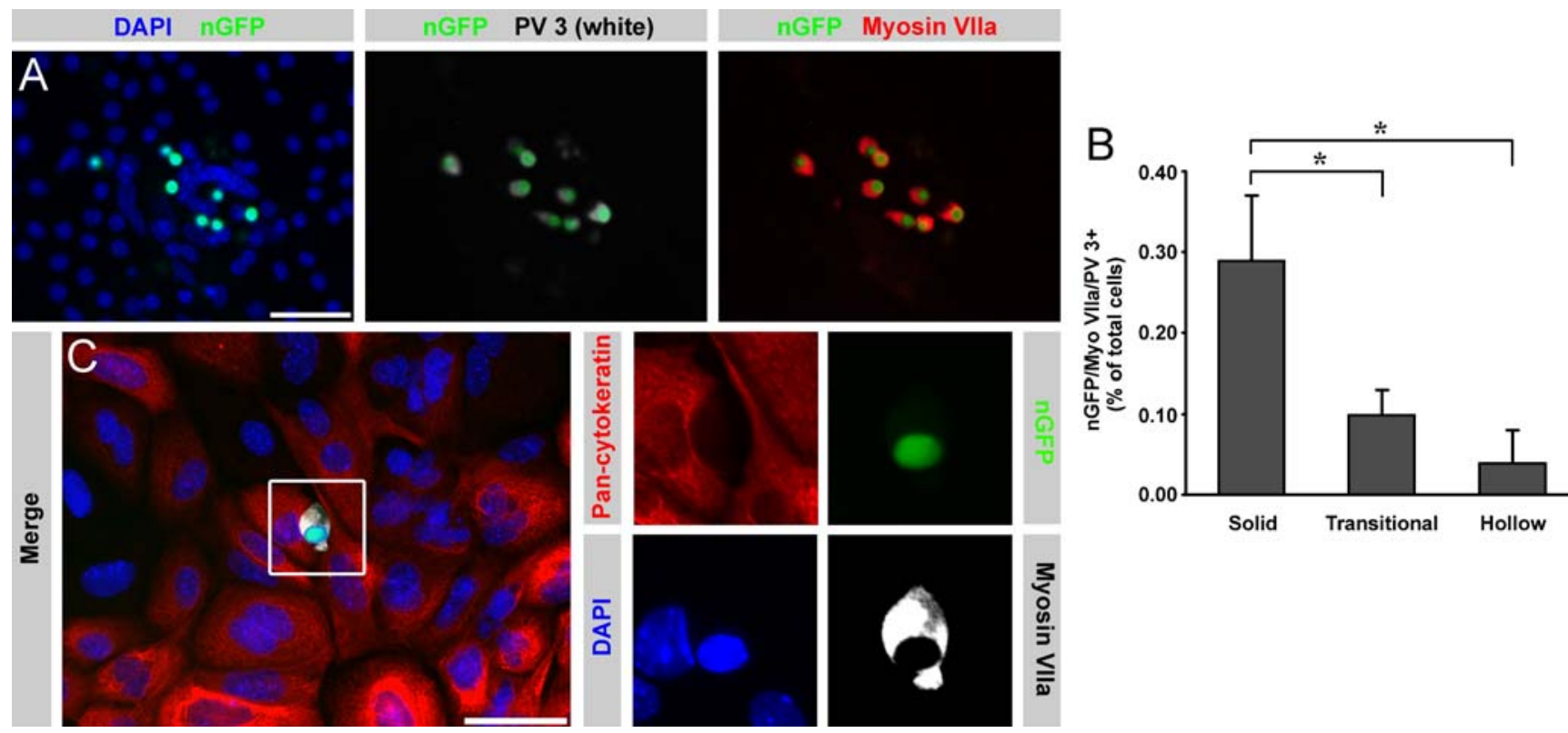

FIG. 12. Differentiation of cochlear sensory epithelium-derived sphere cell populations into cells with characteristics of hair cells and supporting cells. A Hair cell-like cells, characterized by nGFP expression (green) indicating activation of the Atoh1 promoter and coexpression of the hair cell markers myosin VIla (depicted in red) and parvalbumin 3 (PV3, depicted in white), can be found in differentiated cells from all sphere types after 14 days under adherent conditions (shown is a differentiated cell population derived from a solid sphere). B The distinct sphere types vary significantly in their capacity to spontaneously generate hair cell-like cells in vitro. After a 14-day differentiation period, cell populations derived from solid spheres

2008; Senn et al. 2007; Zhai et al. 2005; Zhang et al. 2007). These morphological differences raised the question of whether the different sphere types arise from different proliferative inner ear cells, which could be an indication of different types of stem/ progenitor cells. In this study, we report that the different sphere morphologies are the product of sequential morphological changes from one sphere type into another, which supports the conclusion that sphere morphology is not indicative of distinct populations of stem/progenitor cells in the cochlear sensory epithelia. By categorizing three distinct sphere morphologies and by analyzing their distinct features, we show that neonatal cochlear stem/ progenitor cells initially proliferate into small solid spheres. These spheres are detectable $48 \mathrm{~h}$ after culturing cochlear sensory epithelium cells in nonadherent culture dishes. Small solid spheres subsequently undergo a transition into hollow spheres, which is characterized by occurrence of a small hollow space that continuously enlarges until the spheres become completely hollow. This morphological conversion is accompanied by maturation of the sphere cells into a single epithelial cell layer where Ecadherin is prominently upregulated and distributed generated significantly higher numbers of hair cell-like cells when compared to transitional and hollow spheres. Shown are the mean numbers of $\mathrm{nGFP} /$ myosin VIla/parvalbumin 3 triple-positive cells obtained in eight independent experiments with 25 spheres analyzed per experiment. Error bars represent standard deviation. ${ }^{*} P<0.01$. C Differentiated hair cell-like cells from Math-1/nGFP mice after 14 DIV differentiation express the hair cell marker myosin VIla (white) and display nuclear green fluorescence. Shown is the typical cellular organization where hair cell-like cells are characteristically found on top of pan-cytokeratin-positive cells (red). Nuclei are visualized with DAPI staining (blue). Scale bar $=100 \mu \mathrm{m}$ for $\mathbf{A}$ and $50 \mu \mathrm{m}$ for $\mathbf{C}$.

to adherens junctions. In comparison, solid spheres contain cells that do not display mature epithelial phenotypes. Dissociation of hollow spheres and culture of the resulting sphere cells did not consistently result in sustained growth of new spheres, which is an indication that cells with stem cell features are scarce in hollow spheres. Solid spheres, on the other hand, were propagatable, as shown previously (Oshima et al. 2007; Senn et al. 2007). We consequently conclude that stemness, or the robust capacity to generate a subsequent sphere generation, is lost during the transition of small solid spheres into hollow spheres.

It is interesting to note that solid spheres also occur after 7 DIV or even 12 DIV. We hypothesize that perhaps not all cells with sphere-forming capacity immediately proliferate at the onset of the culture period. Some cells could initially remain in a less proliferative state and these single cells might initiate sphere formation at different time points of the culture period. A similar model describing the relationship between sphere size/morphology and maturation level of the clone-forming cell has been proposed for neurospheres (see Suslov et al. 2002). Similarly, such a delay could be indicative of differences in the phenotypes of cochlear cells with sphere- 


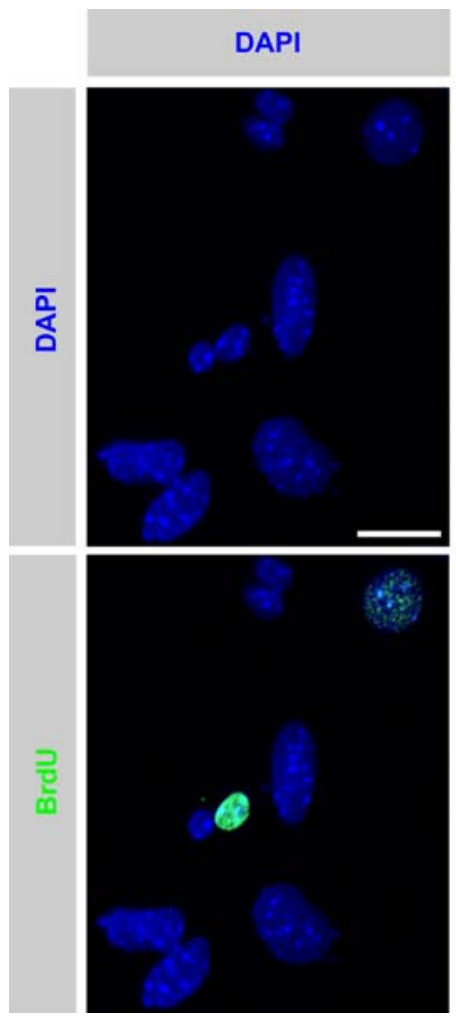

FIG. 13. De novo differentiation of cochlear hair cells from dividing sphere-derived otic progenitors in vitro. Cultures were pulsed with BrdU for $48 \mathrm{~h}$ during sphere formation which led to generation of a small number of BrdU-positive hair cell-like cells (green), characterized by coexpression of the hair cell markers parvalbumin 3 ( $P V 3$, white) and myosin VIla (red). It was not possible to differentiate hair

forming capacity. Either scenario could explain the simultaneous presence of small, solid spheres and large hollow spheres after 7 or 12 DIV.

Previous studies have revealed that organ of Cortiderived solid spheres harbor two to three stem cells that, upon mechanical dissociation of primary spheres, have the ability to generate two to three second-generation spheres (Oshima et al. 2007; Senn et al. 2007). In this study, we report that conversion of solid spheres into hollow spheres is accompanied by a significant reduction of cells that express the embryonic otic progenitor marker Pax-2. In solid spheres, a considerable number of these Pax-2-expressing cells was actively cycling, which indicates that these cells might serve as progenitors for mature inner ear cell types including hair cell-like cells. Pax-2expressing cells are rarely detectable in hollow spheres, and differentiation of hollow spheres did result in significantly reduced numbers of hair cell markerexpressing cells, when compared with solid spheres. This observation supports our hypothesis that hair cell marker-expressing cells might differentiate from Pax-2-expressing sphere cells. It remains to be de- cell-like cells from spheres grown and differentiated in the presence of BrdU at all times, suggesting a cumulative toxic effect of BrdU on sphere cells. Shown is an example of two hair cell-like cells, one showing BrdU incorporation, in a solid sphere-derived cell population after a 14-day differentiation period. Scale bar $=20 \mu \mathrm{m}$.

termined, however, whether the Pax-2-expressing sphere cells are able to generate new spheres after solid sphere dissociation, which would indicate that Pax-2 is a marker for the sphere-forming cells. We speculate that this is probably not the case and that the sphere-forming and self-renewing stem cells in solid spheres are distinctively different from the Pax2-expressing cells. We base this speculation on known facts of otic development where Pax-2-expressing otic progenitors are presumably committed toward the otic lineage (Groves and Bronner-Fraser 2000). Likewise, it is difficult to envision that Pax-2-expressing progenitors display pluripotency, which we previously demonstrated by grafting spheres into gastrulating chicken embryos, albeit these experiments were done with spheres generated from vestibular sensory epithelia $(\mathrm{Li}$ et al. 2003). We consequently hypothesize that solid spheres contain cycling Pax-2-positive otic progenitors as well as an unidentified population of two to three stem cells. A potential candidate population for these stem cells could be cells that express the ATP-binding cassette transporter Abcg2 and Musashi1. These neural stem cell markers are expressed by a subset of sphere-forming 
cells that can be isolated from neonatal cochlear supporting cells via Hoechst dye exclusion and fluorescence-activated cell sorting (Savary et al. 2007).

The otic progenitor cell marker islet-1, on the other hand, is much more abundant in spheres than Pax-2. This is interesting because, during otic development, islet-1 becomes upregulated in nascent sensory epithelia when Pax-2 expression disappears (Huang et al. 2008; Li et al. 2004b). Indeed, only a small subset of Pax-2-positive sphere cells coexpressed islet-1. One explanation for this result is that a large proportion of sphere cells, particularly in solid spheres, which harbor the highest number of islet-1positive cells, could be phenotypically similar to nascent sensory epithelia. If this would be the case, it is puzzling that only a few cells upregulate hair cell markers, which could mean that sphere-derived populations lack certain hair cell-inducing signals or that a large number of the islet-1-expressing cells are incapable of differentiating into hair cell-like cells. It is unlikely that the islet-1-positive sphere cells are neural progenitors because we only occasionally detect cells with neuronal morphology that express neuronspecific markers after differentiation of cochlear sensory epithelium-derived spheres (data not shown).

In summary, we define three morphologically distinct sphere types that form in nonadherent cultures of neonatal cochlear sensory epithelium. Only the population of small solid spheres that occurs predominantly during the first days of nonadherent culture displays the classic features of stem cell-derived spheres, such as the robust ability for self-renewal. Two other sphere types, classified as transitional and buoyant hollow spheres, are derived from solid spheres. The transformation of solid spheres into hollow spheres is associated with the appearance of mature epithelial markers and cytomorphology as well as with the loss of stemness, which was manifested in a decreased propagation ability of the hollow sphere type. Our results provide an explanation for the different sphere types that can be observed in cultures of neonatal cochlear sensory epithelial cells; they also suggest that the solid sphere type is more suitable than the transitional and hollow sphere types for grafting experiments aimed at hair cell regeneration.

\section{ACKNOWLEDGEMENTS}

We thank the members of our research group, particularly Anthony Peng, for the valuable discussions and for the suggestions on the manuscript. We are grateful to Dr. LydiaMarie Joubert of the Stanford EM core facility for the expert assistance. We gratefully acknowledge Drs. Thomas Lenarz and Stephen G. Lisberger for their roles in comentoring M.D. This work was supported in part by a Feodor Lynen research fellowship from the Alexander-von-Humboldt Foundation to
M.D., a Stanford Dean's fellowship award to M.D., as well as grant DC006167 from the National Institutes of Health to S.H.

\section{REFERENCES}

CoRwIN JT. Postembryonic production and aging in inner ear hair cells in sharks. J. Comp. Neurol. 201:541-553, 1981.

CoRwIN JT. Perpetual production of hair cells and maturational changes in hair cell ultrastructure accompany postembryonic growth in an amphibian ear. Proc. Natl. Acad. Sci. U. S. A. 82:3911-3915, 1985

CORWIn JT, COTANCHE DA. Regeneration of sensory hair cells after acoustic trauma. Science 240:1772-1774, 1988

Cotanche DA. Regeneration of hair cell stereociliary bundles in the chick cochlea following severe acoustic trauma. Hear. Res. 30:181-195, 1987.

Cruz RM, Lambert PR, Rubel EW. Light microscopic evidence of hair cell regeneration after gentamicin toxicity in chick cochlea. Arch. Otolaryngol. Head Neck Surg. 113:1058-1062, 1987.

Forge A, Li L, Corwin JT, NevilL G. Ultrastructural evidence for hair cell regeneration in the mammalian inner ear. Science 259:1616-1619, 1993.

Groves AK, Bronner-Fraser M. Competence, specification and commitment in otic placode induction. Development 127:3489-3499, 2000.

Heller S, Bell AM, Denis CS, Choe Y, Hudspeth AJ. Parvalbumin 3 is an abundant $\mathrm{Ca} 2+$ buffer in hair cells. J. Assoc. Res. Otolaryngol. 3:488-498, 2002

Holtmann M, Thurm U. Variations of concentric hair cells in a Cnidarian sensory epithelium (Coryne tubulosa). J. Comp. Neurol. 432:550-563, 2001.

Huang M, Sage C, Li H, Xiang M, Heller S, Chen ZY. Diverse expression patterns of LIM-homeodomain transcription factors (LIM-HDs) in mammalian inner ear development. Dev. Dyn. 237:3305-3312, 2008.

Langemann U, Hamann I, Friebe A. A behavioral test of presbycusis in the bird auditory system. Hear. Res. 137:68-76, 1999.

Lawlor P, Marcotti W, Rivolta MN, Kros CJ, Holley MC. Differentiation of mammalian vestibular hair cells from conditionally immortal, postnatal supporting cells. J. Neurosci. 19:9445-9458, 1999

Li H, Liv H, Heller S. Pluripotent stem cells from the adult mouse inner ear. Nat. Med. 9:1293-1299, 2003.

Li H, Liu H, Corrales CE, Mutai H, Heller S. Correlation of Pax-2 expression with cell proliferation in the developing chicken inner ear. J. Neurobiol. 60:61-70, 2004a.

Li H, Liu H, Sage C, Huang M, Chen ZY, Heller S. Islet-1 expression in the developing chicken inner ear. J. Comp. Neurol. 477:1-10, 2004b.

Lopez-SChiER H, Hudspeth AJ. A two-step mechanism underlies the planar polarization of regenerating sensory hair cells. Proc. Natl. Acad. Sci. U. S. A. 103:18615-18620, 2006.

Lumpkin EA, Collisson T, Parab P, Omer-Abdalla A, Haeberle H, Chen P, Doetzlhofer A, White P, Groves A, Segil N, Johnson JE. Math1-driven GFP expression in the developing nervous system of transgenic mice. Gene Expr. Patterns 3:389-395, 2003.

Malgrange B, Belachew S, Thiry M, Nguyen L, Rogister B, Alvarez ML, Rigo JM, Van De Water TR, Moonen G, Lefebvre PP. Proliferative generation of mammalian auditory hair cells in culture. Mech. Dev. 112:79-88, 2002.

Martin SJ, Reutelingsperger CP, McGahon AJ, Rader JA, van Schie RC, LAFACE DM, GREEN DR. Early redistribution of plasma membrane phosphatidylserine is a general feature of apoptosis regardless of the initiating stimulus: inhibition by overexpression of Bcl-2 and Abl. J. Exp. Med. 182:1545-1556, 1995. 
Martinez-Monedero R, Yi E, Oshima K, Glowatzki E, Edge AS. Differentiation of inner ear stem cells to functional sensory neurons. Dev. Neurobiol. 68:669-684, 2008.

Nornes HO, Dressler GR, Knapik EW, Deutsch U, Gruss P. Spatially and temporally restricted expression of Pax2 during murine neurogenesis. Development 109:797-809, 1990.

Oshima K, Grimm CM, Corrales CE, Senn P, Martinez Monedero R, Geleoc GS, Edge A, Holt JR, Heller S. Differential distribution of stem cells in the auditory and vestibular organs of the inner ear. J. Assoc. Res. Otolaryngol. 8:18-31, 2007.

Oshima K, SENN P, HeLler S. Isolation of sphere-forming stem cells from the mouse inner ear. Methods Mol. Biol. 493:141-162, 2009.

Reynolds BA, Rietze RL. Neural stem cells and neurospheres-reevaluating the relationship. Nat. Methods 2:333-336, 2005.

Ryals BM, Rubel EW. Hair cell regeneration after acoustic trauma in adult Coturnix quail. Science 240:1774-1776, 1988.

Savary E, Hugnot JP, Chassigneux Y, Travo C, Duperray C, Van De WATER T, Zine A. Distinct population of hair cell progenitors can be isolated from the postnatal mouse cochlea using side population analysis. Stem Cells 25:332-339, 2007.

Savary E, Sabourin JC, Santo J, Hugnot JP, Chabbert C, Van De Water T, UzIel A, Zine A. Cochlear stem/progenitor cells from a postnatal cochlea respond to Jagged1 and demonstrate that notch signaling promotes sphere formation and sensory potential. Mech. Dev. 125:674-686, 2008.

Senn P, Oshima K, Teo D, Grimm C, Heller S. Robust postmortem survival of murine vestibular and cochlear stem cells. J. Assoc. Res. Otolaryngol. 8:194-204, 2007.
Suslov ON, Kukekov VG, Ignatova TN, Steindler DA. Neural stem cell heterogeneity demonstrated by molecular phenotyping of clonal neurospheres. Proc. Natl. Acad. Sci. U. S. A. 99:1450614511, 2002.

Torres M, Gomez-Pardo E, Gruss P. Pax2 contributes to inner ear patterning and optic nerve trajectory. Development 122:33813391, 1996.

Warchol Me, Lambert PR, Goldstein BJ, Forge A, Corwin JT. Regenerative proliferation in inner ear sensory epithelia from adult guinea pigs and humans. Science 259:1619-1622, 1993.

WATSON GM, Mire P. A comparison of hair bundle mechanoreceptors in sea anemones and vertebrate systems. Curr. Top. Dev. Biol. 43:51-84, 1999.

White PM, Doetzlhofer A, Lee YS, Groves AK, Segil N. Mammalian cochlear supporting cells can divide and trans-differentiate into hair cells. Nature 441:984-987, 2006.

Whitlon DS. E-cadherin in the mature and developing organ of Corti of the mouse. J. Neurocytol. 22:1030-1038, 1993.

Zhai S, Shi L, Wang BE, Zheng G, Song W, Hu Y, Gao WQ. Isolation and culture of hair cell progenitors from postnatal rat cochleae. J. Neurobiol. 65:282-293, 2005.

Zhang Y, Zhai SQ, Shou J, Song W, Sun JH, Guo W, Zheng GL, Hu YY, GAO WQ. Isolation, growth and differentiation of hair cell progenitors from the newborn rat cochlear greater epithelial ridge. J. Neurosci. Methods 164:271-279, 2007.

Zheng JL, Helbig C, GaO WQ. Induction of cell proliferation by fibroblast and insulin-like growth factors in pure rat inner ear epithelial cell cultures. J. Neurosci. 17:216-226, 1997. 